\title{
Triazole Sensitivity in a Contemporary Population of Fusarium graminearum from New York Wheat and Competitiveness of a Tebuconazole-Resistant Isolate
}

Pierri Spolti, Department of Plant Pathology and Plant-Microbe Biology, Cornell University, Ithaca NY 14853-5904, and Departamento de Fitossanidade, Universidade Federal do Rio Grande do Sul, Porto Alegre, RS 91540000, Brazil; Emerson M. Del Ponte, Departamento de Fitossanidade, Universidade Federal do Rio Grande do Sul; Yanhong Dong, Department of Plant Pathology, University of Minnesota, St. Paul 55108; and Jaime A. Cummings and Gary C. Bergstrom, Department of Plant Pathology and PlantMicrobe Biology, Cornell University

\begin{abstract}
Spolti, P., Del Ponte, E. M., Dong, Y., Cummings, J. A., and Bergstrom, G. C. 2014. Triazole sensitivity in a contemporary population of Fusarium graminearum from New York wheat and competitiveness of a tebuconazole-resistant isolate. Plant Dis. 98:607-613.

A sample of 50 isolates, including 25 each of the 3-acetyldeoxynivalenol and the 15-acetyldeoxynivalenol trichothecene genotype, from a contemporary collection of Fusarium graminearum associated with Fusarium head blight (FHB) of wheat in New York varied in sensitivity to tebuconazole (effective concentration leading to a $50 \%$ reduction of mycelial growth $\left[\mathrm{EC}_{50}\right]$ of 0.28 to $8.09 \mathrm{mg} / \mathrm{liter} ; \mu=1.12 \mathrm{mg} / \mathrm{liter}$ ) and metconazole ( 0.05 to $0.86 \mathrm{mg} /$ liter; $\mu=0.33$ ). Mean sensitivity did not differ between the trichothecene genotype groups. Isolate Gz448NY11 from Steuben County is the first tebuconazole-resistant field isolate of F. graminearum reported in the Americas and has the lowest sensitivity to tebuconazole $\left(\mathrm{EC}_{50}=8.09 \mathrm{mg} / \mathrm{liter}\right)$ documented for this species. Suppression of FHB and deoxynivalenol (DON) following application

of a commercial rate of tebuconazole was significantly diminished in plants inoculated with the tebuconazole-resistant isolate compared with those inoculated with a tebuconazole-sensitive isolate well documented for its aggressiveness and toxigenicity on wheat. There was no diminution of FHB and DON suppression with either isolate following application of metconazole. Significantly more individuals of the tebuconazole-resistant isolate were recovered from spikes inoculated with an equal mixture of the two isolates and sprayed with tebuconazole. Future studies are needed on the epidemiology and monitoring of triazole-resistant isolates to understand the risk that fungicide resistance poses to disease management and food security.
\end{abstract}

Fusarium head blight (FHB) is a disease of increasing concern for cereal crop production worldwide. Epidemics of FHB result in yield losses and, most importantly, contaminate grain with mycotoxins that pose a serious threat to human and animal health $(18,32)$. The main cause of the disease in the Americas is Fusarium graminearum sensu lato $(2,35,43)$, an ascomycete that infects the plant during its reproductive stages and produces a range of mycotoxins during infection and colonization of the developing kernels (10). Deoxynivalenol (DON), a trichothecene compound, is of greatest health and economic concern, given its relatively large amounts detected in epidemic years and mycotoxin concentration limits in foods and feeds in several countries $(18,32)$.

In North America, $F$. graminearum sensu stricto (hereafter $F$. graminearum) is the dominant species associated with FHB epidemics in wheat $(18,32,43,54)$. Polymerase chain reaction (PCR) primers targeting portions of genes related to trichothecene synthesis can be used to genotype isolates as predictive of the trichothecene chemotype, most commonly to determine the 3-acetyldeoxynivalenol (3-ADON), 15-ADON, or nivalenol (NIV) chemotypes $(7,53)$. Both the DON and the NIV genotypes have been found in all surveyed regions and, between the two acetylates of DON, 15ADON appears to be dominant in North America $(6,43,54)$. Nevertheless, studies in some regions of North America suggested an apparent temporal or spatial shift from the 15-ADON to the 3ADON genotype $(6,54)$, which could be related to pathogenic and

Corresponding author: G. C. Bergstrom, E-mail: gcb3@ cornell.edu

* The $\boldsymbol{e}$-Xtra logo stands for "electronic extra" and indicates that a supplementary figure is available online.

Accepted for publication 12 November 2013.

http://dx.doi.org/10.1094/PDIS-10-13-1051-RE

(C) 2014 The American Phytopathological Society toxigenic advantages for 3-ADON compared with 15-ADON isolates $(16,39,49,54)$. None of these studies stressed possible differences in fungicide sensitivity between 15-ADON and 3-ADON isolates.

Although cultural practices such as crop rotation and residue management and the use of less-susceptible commercial varieties each contribute to a reduction in FHB risk, chemical control also provides an effective way to reduce the disease or mycotoxin levels $(4,57)$. FHB is best controlled with triazole fungicides $(34,36,37)$, which inhibit the cytochrome P450 sterol 14 $\alpha$-demethylase (cyp51) and, thereby, affect ergosterol biosynthesis (28). Triazole fungicides, together with imidazoles, piperazine, pyridine, and pyrimidine fungicides that act at the same target site, are grouped as demethylation inhibitors (DMIs; 24).

Among triazoles, tebuconazole has been used in North America since the late 1990s for controlling FHB as well as foliar diseases in cereals (32). Also, propiconazole, metconazole, and prothioconazole can suppress FHB and DON, and are often applied at rates higher than those used for control of foliar diseases (56). In a quantitative summary of fungicide efficacy data from uniform trials in the United States, the commercial mixture of prothioconazole + tebuconazole provided the greatest average reduction in the FHB level, and metconazole provided the greatest average reduction in DON levels (36). It has been hypothesized that the high variability in efficacy among triazole fungicides and even for a single triazole fungicide tested in different locations may be related to variation in triazole sensitivity within and among fungal populations (36).

DMI-resistant fungal pathogens have been reported in populations of Botrytis cinerea (46), Venturia inaequalis (22), Blumeria graminis f. sp. tritici (19), Mycosphaerella graminicola (30), Colletotrichum cereale (58), and $F$. graminearum (59). Studies relate reduction in DMI sensitivity to mutations in and overexpression of the cyp51 gene (26,59). Molecular characterization of a tebuconazole-resistant (effective concentration leading to a $50 \%$ reduction of mycelial growth $\left[\mathrm{EC}_{50}\right]=6.2 \mathrm{mg} /$ liter) isolate of $F$. 
graminearum from China did not reveal mutations in the paralogous cyp $51 a$ gene associated with reduced sensitivity to tebuconazole (59). Triazole-resistance in $F$. graminearum populations was also reported in Europe, where a gradual decrease in sensitivity to tebuconazole over a decade of more intensive use of this fungicide was documented (21).

The increase in frequency of resistant individuals in field populations depends on fungicide selective pressure and the absence of fitness costs associated with a reduction in fungicide sensitivity $(20,23,47)$. A laboratory study highlighted the potential of $F$. graminearum isolates to adapt and become resistant to tebuconazole fungicide after several generations were exposed to the fungicide (3). Furthermore, some of the mutant isolates were not affected in their reproductive fitness and, most seriously, the resistant isolates produced more NIV mycotoxin than the wild isolates (3).

In the face of increasing use of triazole fungicides for FHB control and the demonstrated risk of fungicide resistance, there is an urgent need to monitor field populations of $F$. graminearum for the presence of triazole-resistant isolates and to assess comparatively their aggressiveness and toxigenic potential. Such survey data are scarce in the literature; there is only one report of triazole-resistant isolates detected in China (59) and resistant strains of $F$. graminearum were not found in a field survey conducted in Brazil (45). In the United States, a preliminary report described variation in sensitivity of $F$. graminearum isolates from wheat to tebuconazole and prothioconazole but no resistant isolates were identified (52).

The objectives of this study were twofold: (i) determine the sensitivity to tebuconazole and metconazole in a contemporary population of $F$. graminearum associated with symptomatic wheat spikes in western New York in 2011 and (ii) assess whether the sensitivity varies according to the trichothecene genotype (3ADON or 15-ADON). During the conduct of this study, a single tebuconazole-resistant isolate was found; therefore, this isolate was further compared with a reference tebuconazole-sensitive isolate for competitiveness during pathogenesis in the presence and absence of triazole fungicide applications.

\section{Materials and Methods}

Fungal isolates. Fifty $F$. graminearum isolates were selected from a large collection of isolates obtained from wheat spikes with FHB symptoms in a survey conducted in western New York wheat fields in 2011 (G. C. Bergstrom, unpublished) and identified as Btrichothecene genotypes based on PCR assays targeting Tri3 and Tri12 genes (53). Half of the selected isolates were of the 3-ADON genotype and the other half of the 15-ADON genotype. In addition, a previously characterized, highly aggressive and toxigenic $F$. graminearum isolate (Gz014NY98) that has been utilized in both controlled-environment $(11,13,40)$ and field studies $(12,55)$ in New York for many years was included in this study. For all assays, the fungi were cultured on potato dextrose agar (PDA; Difco Laboratories) under fluorescent light (type C-14; Underwriters Laboratories Inc.) with a 12-h photoperiod.

Fungicide sensitivity assay. The two triazole fungicides tested were aqueous suspensions of commercially formulated tebuconazole (Onset 3.6 1; Winfield Solutions) and metconazole (Caramba; BASF Corporation). The fungicide sensitivity of the isolates was determined by assessing mycelial growth via an agar dilution method $(3,45,59)$. Molten PDA media was cooled to 45 to $50^{\circ} \mathrm{C}$, and stock solutions of the fungicides in sterile distilled water were added. The tested concentrations for both fungicides were $0,0.003$, $0.1,0.3,1,3,10$, and $30 \mathrm{mg}$ a.i./liter. In the mycelial growth assays, one mycelial agar plug from the edge of a culture of each isolate (7-day-old cultures) was placed in the center of a petri dish (90 $\mathrm{mm}$ ) containing $7 \mathrm{ml}$ of PDA amended with the fungicide $(3,59)$. For each combination of isolate-dose-fungicide, three replicates (petri dishes) were used. Radial growth was measured after incubation at $25^{\circ} \mathrm{C}$ for 4 days in the dark. The experiment was conducted twice.

Fungal growth was expressed as percent inhibition relative to growth on unamended agar. The $\mathrm{EC}_{50}$ was calculated on the basis of linear regression analysis between the relative mycelial growth inhibition (percent) and the log-transformed fungicide concentrations $(3,45,59)$. Because the two experiments did not differ significantly $(P>0.05$, Fisher's least significant difference [LSD] test), $\mathrm{EC}_{50}$ data were combined for the analysis. Resistance factors (23) were calculated by dividing the $\mathrm{EC}_{50}$ of the less-sensitive isolate by the $\mathrm{EC}_{50}$ of the most-sensitive isolate for both fungicides and for each trichothecene genotype.

During the conduct of this study, a single isolate (Gz448NY11) was found with the highest $\mathrm{EC}_{50}$ in the literature $(8.09 \mathrm{mg} / \mathrm{liter})$ and was considered tebuconazole-resistant (TEB-R). Further experiments were conducted to compare its pathogenicity, toxigenic potential, and competitiveness with a tebuconazole-sensitive (TEBS) isolate ( $\mathrm{Gz} 014 \mathrm{NY} 98)$.

Trichothecene production in rice culture. Mycotoxin production by the resistant isolate and a reference sensitive isolate was assessed following a standard protocol (39). Briefly, rice grains (30 g) were soaked in deionized distilled water overnight $(10 \mathrm{~h})$ in a 250-ml Erlenmeyer flask. After autoclaving, three agar plugs of fresh growing mycelia from PDA cultures (5 days old) were added to the rice substrate. Four flasks (replicate units) were prepared for each isolate. The cultures were grown in the dark for 30 days at $22^{\circ} \mathrm{C}$. The colonized substrate was then transferred into a $50-\mathrm{ml}$ centrifuge tube, stored at $-80^{\circ} \mathrm{C}$ overnight, and lyophilized for 6 days at $-40^{\circ} \mathrm{C}$. Prior to analysis, the colonized rice substrates were ground and a 5-g sample of each replicate was used for the mycotoxin quantification. The amount of DON and its acetylated forms (3-ADON and 15-ADON) was quantified for each sample by gas chromatography-mass spectrometry (GC-MS; 15).

Competitiveness assay. The TEB- $R$ isolate was evaluated in regard to its competitive ability when inoculated together with a TEB-S isolate (Gz014NY98), previously documented as highly aggressive and toxigenic on wheat. Seed of 'Norm', a spring wheat variety highly susceptible to FHB, were sown in 15.3 -cm-diameter clay pots (10 seeds/pot) filled with soilless Cornell Mix (97 liters of compressed peat moss, 114 liters of vermiculite, $9.1 \mathrm{~kg}$ of dolomitic limestone, and $2.7 \mathrm{~kg}$ of $11-5-11 \mathrm{~N}-\mathrm{P}-\mathrm{K}$ fertilizer). Plants were grown for 8 weeks in the greenhouse at 20 to $25^{\circ} \mathrm{C}$ under 12 to $14 \mathrm{~h}$ of light per day and trimmed to keep the 10 main tillers in each pot (11). At early milk stages, the plants were sprayed with tebuconazole (113 g a.i./ha, Onset 3.6 1; Winfield Solutions) or metconazole $(0.41 \mathrm{~g}$ a.i./ha, Caramba; BASF Corporation) fungicides. Both fungicide-treated and nontreated plants (check treatment) were kept in the greenhouse for $48 \mathrm{~h}$ and spray inoculated with three distinct inoculum compositions: the TEB-R and TEB-S isolates inoculated individually or in mixture (1:1, TEB-S/TEB-R).

A macroconidal suspension $\left(2 \times 10^{5}\right.$ conidia/ml $)$ was applied uniformly on wheat spikes using a household handheld sprayer (Consolidated Plastics) at a rate of approximately $1 \mathrm{ml} / \mathrm{head}$. After drying, inoculated plants were covered with a plastic bag and kept for $48 \mathrm{~h}$ in a growth chamber set at $25.5^{\circ} \mathrm{C}$ and a cycle of 14 and 9 $\mathrm{h}$, light and darkness, respectively. The bags were then removed and the plants remained in the same chamber until harvest (approximately 40 days after inoculation). Assessments of disease incidence and severity were made at 4, 7, and 10 days after inoculation in four potted plants (replicates) per treatment.

At kernel maturity, grains were harvested, hand threshed, and ground to a fine powder using a coffee grinder. The amount of DON, 3-ADON, and 15-ADON was quantified as previously described. From the spikes inoculated with the equal mixture of isolates (TEB-S/TEB-R), 165 cultures (each from a single kernel) were recovered from both the fungicide-treated and nontreated plants. Single-spore subcultures were grown from the recovered cultures and identified as one of the two inoculated isolates based on a vegetative compatibility assay (31). Four mycelial plugs of a recovered isolate were placed equidistantly around the outer edge of a petri dish filled with V8-wheat medium ( $150 \mathrm{ml}$ of V8 juice, $20 \mathrm{~g}$ of ground wheat seed, and $20 \mathrm{~g}$ of agar per 1 liter of medium; 31). A mycelial plug of either isolate was placed at the center of 
the plates, which were incubated at room temperature $\left(22^{\circ} \mathrm{C}\right)$ and continuous light. The presence of barrage zones, indicative of an incompatible reaction at the junctions of growing colonies, was recorded after 10 days of incubation to identify the recovered isolates. In preliminary tests (data not shown), the TEB-R and TEB-S isolates always showed an absence of barrage zones when paired with their clonal cultures and the presence of barrage zones when paired with clonal cultures of the other isolate.

Data analysis. A randomized complete block design with four replicates (four pots of each treatment) was used to analyze data from the competitiveness assay. A mixed-effects model with maximum likelihood estimation was fitted to the data of area under the disease progress curve (AUDPC), thousand-kernel weight (TKW), Fusarium-damaged kernels (FDKs), and trichothecene amount (DON, 15-ADON, and 3-ADON) in grains, using SAS PROC MIXED (SAS Institute). Means were compared using Fischer's least significant difference (LSD) $(\alpha=0.05)$. In the competitiveness assay the recovery rates of the TEB-S and TEB-R isolates from inoculated plants with a 1:1 mixture of the two and fungicide treated or nontreated wheat plants were checked using a $\chi^{2}$ test $(\alpha$ $=0.05$ ). For assessment of cross-resistance between tebuconazole and metconazole, $\mathrm{EC}_{50}$ values were transformed to logarithmic values $\left(\log \mathrm{EC}_{50}\right)$ and subjected to Spearman's rank correlation analysis $(\alpha=0.05)$.

\section{Results}

Sensitivity to tebuconazole and metconazole. $\mathrm{EC}_{50}$ values were 0.28 to $8.09 \mathrm{mg} / \mathrm{liter}$ for tebuconazole and 0.05 to 0.86 $\mathrm{mg} / \mathrm{liter}$ for metconazole. Two isolates (Gz448NY11, with a 15ADON genotype, and Gz546NY11, with a 3-ADON genotype) showing the largest $\mathrm{EC}_{50}$ values for tebuconazole (8.09 and 2.46 $\mathrm{mg} /$ liter, respectively), differed significantly from all other isolates and from each other (LSD $[\alpha=0.05]=0.40 \mathrm{mg} / \mathrm{liter})$. For metconazole, only one isolate-Gz830NY11 (3-ADON), with the largest $\mathrm{EC}_{50}(0.86 \mathrm{mg} / \mathrm{liter})$ - differed significantly from the other isolates (LSD $[\alpha=0.05]=0.12 \mathrm{mg} / \mathrm{liter}$ ).

The fungitoxicity of metconazole was greater than tebuconazole $\left(P<0.001\right.$; Fig. 1). The mean $\mathrm{EC}_{50} \pm$ C.I. (confidence interval) $95 \%$ was $1.12 \pm 0.30$ and $0.33 \pm 0.05$ for tebuconazole and metconazole, respectively. The resistance factor of tebuconazole and metconazole was 29.21 and 15.94 , respectively. The $\mathrm{EC}_{50}$ varied considerably among the isolates of each trichothecene genotype group $(P<0.001 ;$ Fig. 1$)$ and no difference for the $\mathrm{EC}_{50}$ was detected between the $3-\mathrm{ADON}$ and the $15-\mathrm{ADON}$ isolates. However, the resistance factor of $15-\mathrm{ADON}$ isolates was greater than 3-ADON isolates for both fungicides but especially for tebuconazole. Cross-resistance between these two triazoles was inferred based on the significance of the Spearman's correlation coefficient $(R=0.30, P=0.03)$. In rice culture, the toxigenic potential of the TEB-R isolate was confirmed with chemical analysis; it produced even larger amounts of $15-\mathrm{ADON}(P=0.02$; $816.4 \mathrm{mg} / \mathrm{kg})$ and DON $(P=0.03 ; 330.1 \mathrm{mg} / \mathrm{kg})$ than the TEB-S isolate $(15-\mathrm{ADON}=107.5 \mathrm{mg} / \mathrm{kg}$ and $\mathrm{DON}=35.4 \mathrm{mg} / \mathrm{kg})$ documented as a large DON producer. Both isolates $(P=0.49)$ produced only small amounts of 3-ADON: 1.17 and $0.52 \mathrm{mg} / \mathrm{kg}$ by the TEB-R and TEB-S isolates, respectively.

Fungicide efficacy toward resistant and sensitive isolates. In the no-fungicide treatment, no significant difference was found for any variable when the mixture of isolates was inoculated (Tables 1 and 2). Both triazoles reduced disease intensity and mycotoxin concentration but metconazole provided the best control (Table 2). When tebuconazole was applied, disease control, kernel damage, and trichothecene concentration in kernels were influenced by the inoculum composition (Supplementary Figure 1; Table 1).

For plants inoculated with the TEB-S alone and TEB-R alone, disease control efficacy, based on AUDPC, was 67 and 18\%, respectively, when tebuconazole was sprayed (Table 1). For the same inoculum treatments, metconazole provided $>95 \%$ control efficacy regardless of the inoculum composition (Table 1). For the tebuconazole-treated plants, mean kernel weight was 18.63 and $12.53 \mathrm{~g}$ (LSD $[0.05]=3.73 \mathrm{~g}$ ) following inoculations with the TEB-S and the TEB-R isolate, respectively (Table 1). FDK was less for the TEB-S isolate than for the TEB-R isolate (Table 1). FDK level for the mixture of isolates was less than for the TEB-R isolate alone (Table 1). For plants treated with tebuconazole, all trichothecenes were in larger concentrations when the TEB-R isolate was inoculated compared with the TEB-S isolate (Table 1). Particularly, DON levels were reduced by 39 and $83 \%$ when the TEB-R and TEB-S isolates, respectively, were inoculated (Table 1). Metconazole effectively reduced trichothecene values below $2 \mathrm{ppm}$ and no significant effect of treatment was found (Table 2). As verified in rice culture, 3-ADON was detected but in much smaller amounts $(<0.9 \mathrm{ppm})$ and tebuconazole-sprayed plants inoculated with the TEB-R isolate produced more 3-ADON than the TEB-S isolate.

Competitiveness assays. In total, 165 single-spored isolates were obtained from kernels inoculated with the mixture of the two

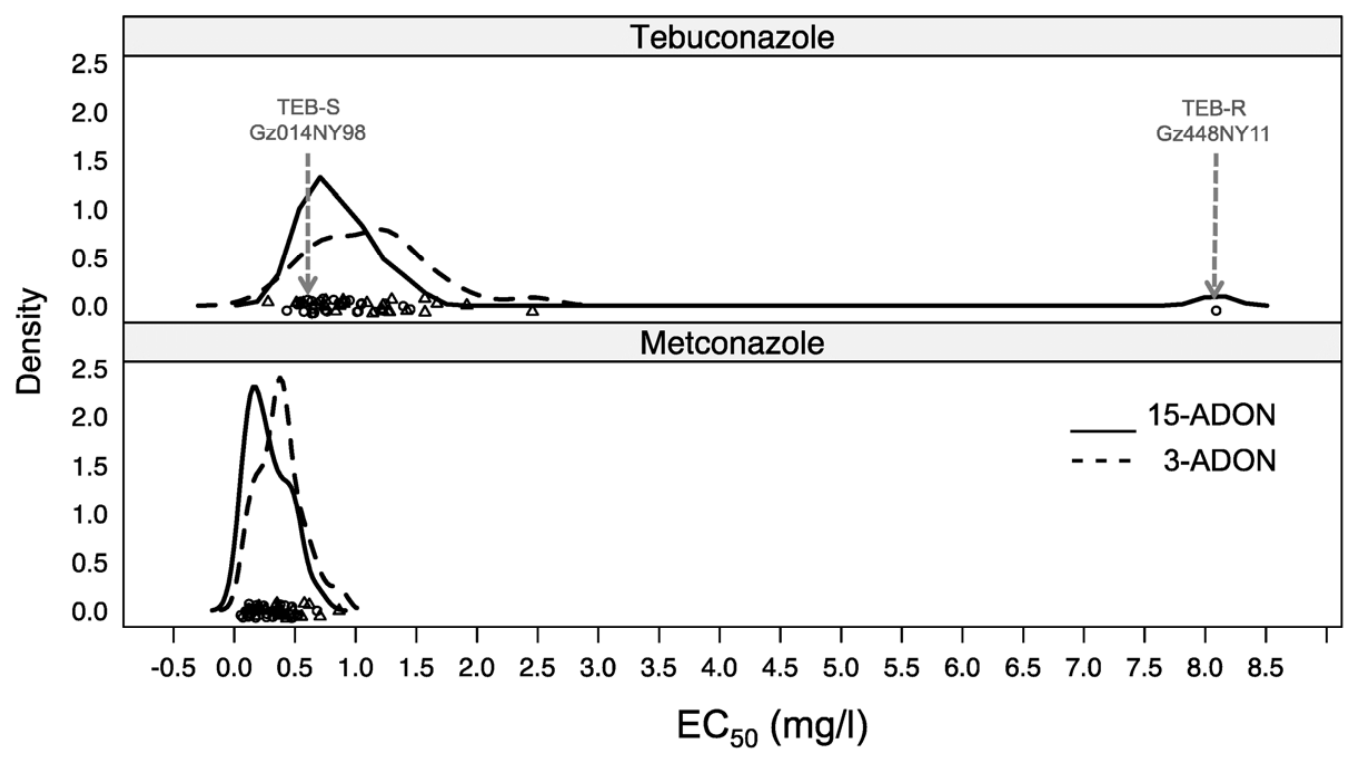

Fig. 1. Density plots, obtained via a gaussian kernel density estimation, of the effective concentration of metconazole and tebuconazole that reduces $50 \%$ of the mycelial growth $\left(\mathrm{EC}_{50}\right)$ in a collection of Fusarium graminearum isolates from New York with distinct trichothecene genotype (15-acetyldeoxynivalenol [ADON] or 3-ADON). Arrows indicate the mean $\mathrm{EC}_{50}$ values for a tebuconazole-sensitive isolate (TEB-S) and a tebuconazole-resistant (TEB-R) isolate that were compared for competitiveness on wheat following triazole application or no application. 
isolates. In the tebuconazole experiment, 50 isolates were from plants sprayed with tebuconazole and 50 from those not sprayed. In the metconazole experiment, 15 isolates were obtained from plants sprayed with metconazole and 50 from those not sprayed (Fig. 2). Because the smallest sample was 15, deviations from the initial 1:1 proportion were evaluated with a minimum probability of $99.6 \%(P \leq 0.004)$, using the formula $\log (p)=\log (1-x)^{\wedge} n$, where $p$ is the significance level, $x$ is the frequency of the expected trait in a sample $(1: 1=0.5)$, and $n$ is the sample size (49). In the absence of the fungicides, there was no deviation from the expected proportion $0.5 / 0.5$ (Fig. 2). However, the frequency of the TEB-R isolate was greater when plants were sprayed with tebuconazole $(0.9 / 0.1$ for the TEB-R and TEB-S isolate, respectively). When metconazole was applied, the proportions of the isolates did not deviate from the original proportion of inoculated isolates.

\section{Discussion}

Triazole fungicides have been used for as long as 30 years for the control of fungal pathogens that cause disease in plants and humans and, in both cases, resistance to some active ingredients has been a noteworthy and emerging issue due to selection pressure and absence of an anti-resistance strategy $(5,8,9,17,38)$. In North America, triazole fungicides have been used for FHB management since the late 1990s (32). Metconazole, prothioconazole, and prothioconazole plus tebuconazole are the most effective options available for FHB control and trichothecene suppression $(36,37)$,

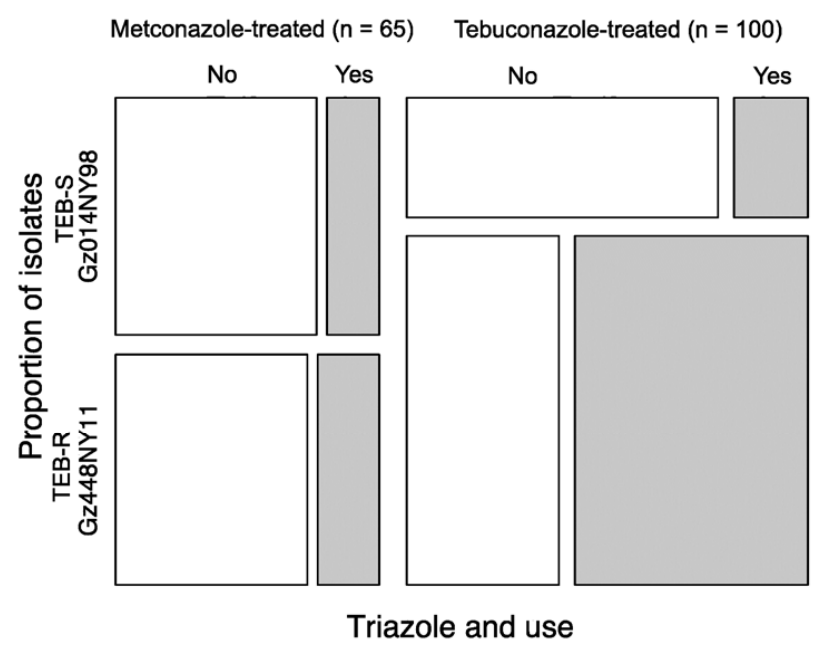

Fig. 2. Mosaic plots for the proportion of tebuconazole-resistant (TEB-R, white fill) and tebuconazole-sensitive (TEB-S, gray fill) isolates recovered from grains of wheat plants inoculated with an equal mixture of these isolates at early milk stage of grain development and treated with metconazole and tebuconazole. Recovered isolates were identified based on the presence of barrage zones in incompatible pair matches (nonclonal). In the tebuconazole-sprayed plants, the recovery rates differed significantly from those expected for a 1:1 mixture according to a $\chi^{2}$ test at $P<0.05 ; n=$ total number of isolates recovered.

Table 1. Fusarium head blight and mycotoxins on wheat plants ('Norm') that were not sprayed or were sprayed with tebuconazole $48 \mathrm{~h}$ before the inoculation with Gz014NY98 (tebuconazole-sensitive, TEB-S), Gz448NY11 (tebuconazole-resistant, TEB-R), or a 1:1 mixture of these two isolates

\begin{tabular}{|c|c|c|c|c|c|c|}
\hline \multirow[b]{2}{*}{ Treatment, inoculum } & \multirow[b]{2}{*}{ AUDPC $^{\mathbf{b}}$} & \multirow[b]{2}{*}{$\mathbf{T K W}^{\mathrm{c}}$} & \multirow[b]{2}{*}{ FDK $^{d}$} & \multicolumn{3}{|c|}{ Trichothecene (ppm) in wheat kernels ${ }^{\mathbf{a}}$} \\
\hline & & & & DON & 15-ADON & 3-ADON \\
\hline \multicolumn{7}{|l|}{ Nonsprayed } \\
\hline TEB-S & 595.41 & 10.40 & 100.00 & 143.3 & 5.13 & 2.73 \\
\hline TEB-R & 596.85 & 9.95 & 100.00 & 202.8 & 3.60 & 2.40 \\
\hline TEB-S + TEB-R & 599.37 & 10.05 & 100.00 & 132.2 & 2.50 & 2.25 \\
\hline $\mathrm{LSD}^{\mathrm{e}}$ & 53.34 & 2.14 & 0.00 & 77.79 & 2.61 & 0.92 \\
\hline \multicolumn{7}{|l|}{ Tebuconazole-sprayed } \\
\hline TEB-S & 196.03 & 18.63 & 70.25 & 23.73 & 0.60 & 0.22 \\
\hline TEB-R & 488.21 & 12.53 & 92.00 & 123.35 & 1.40 & 0.92 \\
\hline TEB-S + TEB-R & 368.31 & 16.55 & 78.00 & 83.90 & 1.31 & 0.77 \\
\hline $\mathrm{LSD}^{\mathrm{e}}$ & 59.87 & 3.73 & 10.48 & 21.32 & 0.61 & 0.32 \\
\hline
\end{tabular}

${ }^{a}$ Trichothecenes in grains from spikes of Norm wheat inoculated in the greenhouse and averaged from four replicates; ppm = part per million $(\mathrm{mg} / \mathrm{kg}$ of samples). $\mathrm{DON}=$ deoxynivalenol and $\mathrm{ADON}=$ acetyldeoxynivalenol.

${ }^{\mathrm{b}}$ Area under disease progress curve (AUDPC) calculated from FHB severity at 4, 7, and 10 days after inoculation.

c $\mathrm{TKW}=$ thousand kernel weight.

${ }^{\mathrm{d}}$ Fusarium-damaged kernels (FDK) visually estimated in a subsample of 100 kernels/replicate.

${ }^{\mathrm{e}}$ Least significant difference (LSD; $P<0.05$ ).

Table 2. Fusarium head blight and mycotoxins on wheat plants ('Norm') that were not sprayed or were sprayed with metconazole $48 \mathrm{~h}$ before the inoculation with Gz014NY98 (tebuconazole-sensitive, TEB-S), Gz448NY11 (tebuconazole-resistant, TEB-R), or a 1:1 mixture of these two isolates

\begin{tabular}{|c|c|c|c|c|c|c|}
\hline \multirow[b]{2}{*}{ Treatment/inoculum } & \multirow[b]{2}{*}{ AUDPC $^{\mathbf{b}}$} & \multirow[b]{2}{*}{ TKW $^{\mathbf{c}}$} & \multirow[b]{2}{*}{ FDK $^{\mathbf{d}}$} & \multicolumn{3}{|c|}{ Trichothecene (ppm) in wheat kernels ${ }^{\mathrm{a}}$} \\
\hline & & & & DON & 15-ADON & 3-ADON \\
\hline \multicolumn{7}{|l|}{ Nonsprayed } \\
\hline TEB-S & 547.18 & 10.21 & 94.25 & 195.70 & 28.78 & 2.35 \\
\hline TEB-R & 550.38 & 9.43 & 93.75 & 266.73 & 38.78 & 3.48 \\
\hline TEB-S + TEB-R & 526.10 & 10.12 & 94.50 & 141.98 & 25.43 & 2.40 \\
\hline $\mathrm{LSD}^{\mathrm{e}}$ & 102.63 & 2.21 & 7.80 & 93.42 & 10.49 & 1.18 \\
\hline \multicolumn{7}{|l|}{ Metconazole-sprayed } \\
\hline TEB-S & 13.70 & 18.85 & 2.00 & 0.46 & 0.18 & $<0.05$ \\
\hline TEB-R & 19.15 & 18.35 & 2.25 & 0.86 & 0.97 & $<0.05$ \\
\hline TEB-S + TEB-R & 16.70 & 17.35 & 1.75 & 1.75 & 0.30 & $<0.05$ \\
\hline $\mathrm{LSD}^{\mathrm{e}}$ & 9.43 & 2.81 & 2.42 & 1.57 & 0.80 & 0.00 \\
\hline
\end{tabular}

${ }^{a}$ Trichothecenes in grains were obtained from spikes of Norm wheat inoculated in the greenhouse and averaged from four replicates; ppm $=$ part per million $(\mathrm{mg} / \mathrm{kg}$ of samples). DON = deoxynivalenol and ADON = acetyldeoxynivalenol.

${ }^{\mathrm{b}}$ Area under disease progress curve (AUDPC) calculated from FHB index at 4, 7, and 10 days after inoculation.

c $\mathrm{TKW}=$ thousand kernel weight.

${ }^{\mathrm{d}}$ Fusarium-damaged kernels (FDK) visually estimated in a subsample of 100 kernels/replicate.

${ }^{\mathrm{e}}$ Least significant difference $(P<0.05)$. 
though generic solo tebuconazole products are still in wide use because of their low price.

Differential sensitivity to fungicides was postulated as one of the factors related to possible adaptive advantages of 3-ADON $F$. graminearum isolates compared with $15-\mathrm{ADON}$ isolates (32). However, no difference in $\mathrm{EC}_{50}$ for tebuconazole and metconazole was observed between isolates of these two genotypes in our study. Furthermore, the resistance factor for both fungicides was greater for 15-ADON isolates than for the 3-ADON isolates, which is consistent with the hypothesis that the native $F$. graminearum population in North America was composed wholly or predominantly of $15-A D O N$ individuals $(53,54)$. Studies with much greater numbers of isolates would be necessary to infer with confidence that there is a significant difference in resistance factor between trichothecene genotypes.

In Brazil, Spolti et al. (45), working with 50 Brazilian isolates of $F$. graminearum, found that the $\mathrm{EC}_{50}$ values were $<0.001$ to 0.15 $\mathrm{mg} / \mathrm{liter}$ for tebuconazole and $<0.001$ to $0.32 \mathrm{mg} / \mathrm{liter}$ for metconazole, and no isolate was identified with resistance to tebuconazole or metconazole. Tebuconazole-resistant $F$. graminearum isolates have been detected in field surveys conducted in China (highest detected $\left.\mathrm{EC}_{50}=6.3 \mathrm{mg} / \mathrm{ml} ; 59\right)$. In Germany, a gradual reduction in sensitivity to tebuconazole was observed in samples of one to three isolates representing three decades (1980 to 2000) based on the germination rate of ascospores exposed to increasing fungicide dose (21).

To our knowledge, this study provides the first documentation of a natural isolate of $F$. graminearum in the Americas with resistance to tebuconazole and the least sensitive $\left(\mathrm{EC}_{50}=8.09 \mathrm{mg} / \mathrm{ml}\right)$ reported in this species. Tebuconazole-based fungicides have been labeled for FHB suppression and foliar disease control in several states of the United States since the late 1990s. Interestingly, tebuconazole foliar fungicides were not available in New York during this interval but tebuconazole-based seed treatments were used widely. Generic tebuconazole formulations continue to be used as foliar sprays in the United States, although tebuconazole is now widely deployed for FHB suppression in the United States, including New York, principally in a commercial mixture with prothioconazole (Prosaro; Bayer CropScience LP) (32). Although the tebuconazole-resistant isolate from wheat in Steuben County, NY, may have been selected locally following exposure to tebuconazole fungicides, it is from a region that has not had intensive use of tebuconazole. Alternatively, given the ability of $F$. graminearum ascospores to be dispersed over long distances in the atmosphere $(29,41,42)$, the TEB-R isolate could have originated from a distant location subjected to greater selection pressure from tebuconazole. However, it is perhaps most likely that the TEB-R isolate persisted in the local population in the absence of significant triazole selection due primarily to the inherently high genotypic diversity of $F$. graminearum $(51,60)$. We suspect that more extensive surveys will reveal that TEB-R and other triazole-resistant isolates occur more commonly than we currently realize.

In the absence of the tebuconazole, the ratio of TEB/R:TEB-S did not deviate from the expected proportion of 50:50\%. However, when plants were sprayed with tebuconazole, the frequency of the TEB-R isolates was greater than the TEB-S. Altogether, these results are indicative of no pathogenic cost associated with the fungicide-resistance trait, and that the TEB-R isolate had greater competitiveness when plants were sprayed with tebuconazole.

Only a few studies have compared reproductive fitness and pathogenic traits for isolates of $F$. graminearum that are either resistant or sensitive to tebuconazole. Most commonly, fungicide resistance is induced in the laboratory by successive exposure of a sensitive isolate to increasing sublethal doses of the tebuconazole fungicide (3). However, studies using nonparental isolates of the same species, which vary naturally in sensitivity to a specific fungicide, may allow a more accurate assessment of the potential effects of this trait on disease control.

The $50 \mathrm{~F}$. graminearum isolates characterized in this study were used in another study where fitness attributes of isolates possessing a $15-\mathrm{ADON}$ or 3 -ADON trichothecene genotype were compared
(P. Spolti et al. [44]). Using 14 variables of saprophytic and pathogenic fitness (for example, mycelial growth rate, temperature sensitivity, perithecia and ascospore formation on corn stalks, and aggressiveness on wheat), the TEB-R isolate (Gz44811) was clustered together with other TEB-S isolates and no clear adaptive cost appeared to be associated with tebuconazole resistance.

Both the TEB-R isolate and the TEB-S reference isolate exhibited a $15-\mathrm{ADON}$ genotype and produced mainly DON and relatively smaller amounts of the two acetylated forms in inoculated wheat grain. It is common in this species that an isolate produces both acetylated DON forms but that the ADON form in highest concentration conforms to the isolate's trichothecene genotype $(1,25,33,39)$. We have no explanation for the relatively greater production of DON and 15-ADON in the nonsprayed plants in the metconazole experiment as compared with the nonsprayed plants in the tebuconazole experiment, except that these experiments were conducted at separate times with presumably subtle differences in environmental conditions.

Interestingly, the TEB-R isolate produced larger amounts of trichothecene toxins than the TEB-S isolate that we used as a standard for comparison and which has been utilized in screening of wheat varieties and for tests of fungicide efficacy because of its history of being a potent DON-producing isolate. The TEB-R isolate also produced moderately larger amounts of trichothecenes in wheat grain than the TEB-S did but not by the ratio observed in rice cultures. One would need to assess a large number of fungal isolates to discern whether fungicide resistance is associated with increased production of trichothecenes; however, there is some basis for forming such a hypothesis. Becher et al. (3) observed an increasing ratio of NIV/fungal biomass produced by TEB-R isolates derived by laboratory selection from a sensitive parental isolate. Correspondingly, carbendazim- $\mathrm{R}$ isolates produced larger amounts of trichothecenes (DON+3-ADON or DON+15-ADON) than carbendazim-S isolates in both liquid media and wheat heads inoculated under field conditions (61).

Biological and agronomic factors such as the high genetic diversity of the pathogen population and increasing use of triazole fungicides in North America may pose a risk of selection of isolates that are both resistant to triazole fungicides and produce large amounts of dangerous mycotoxins, similar to what has been recently reported for Aspergillus parasiticus (14). Although the efficacy of preventive spray of tebuconazole against the subsequently inoculated resistant isolate was strongly reduced, metconazole was highly efficacious for both isolates. Curative sprays of tebuconazole for the control of FHB induced by either a TEB-R or TEB-S isolate were equally effective in another study (3). Such disagreement with our results may be due to differences in the timing of fungicide application and range of fungicide sensitivity between our study and that described by Becher et al. (3).

Becher et al. (3) induced tebuconazole resistance in $F$. graminearum isolates by successively exposing cultures to sublethal doses; the adapted isolates showed an $\mathrm{EC}_{50}$ to tebuconazole in a range of 0.26 to $0.86 \mathrm{mg} / \mathrm{liter}$, which is lower than the naturally tebuconazole-resistant isolate from New York observed in our study and by Yin et al. (59) in Chinese isolates.

In Japan, preventative sprays of metconazole and subsequent inoculation of isolates varying in minimum inhibitory concentration to the fungicide ( 0.25 to $6.25 \mathrm{mg}$ a.i./liter) did not differ in fungicide efficacy regardless of the dose used (10 to $120 \mathrm{~g} / \mathrm{ha}$ ); fungicide efficacy was close to $100 \%$ using the commercial rate, similar to our result when using metconazole (48).

The divergence from the initial frequency of isolates may provide evidence for selective pressure because the sensitive isolate would be less competitive than the resistant one when exposed to the fungicide (23). The competitiveness assay clearly showed that the TEB-R isolate was selected for in the presence of tebuconazole, which was not observed for metconazole, as we expected.

Different DMI fungicides target different Cyp51 proteins in $F$. graminearum (27). Although there was a significant correlation between $\mathrm{EC}_{50}$ for tebuconazole and metconazole over the 50 iso- 
lates, the sensitivity levels for metconazole were rather low $(84 \%$ of the isolates had $\mathrm{EC}_{50}<0.5 \mathrm{mg} / \mathrm{liter}$ ) and the TEB-R isolate from New York was equally sensitive to metconazole $\left(\mathrm{EC}_{50}=0.31\right.$ $\mathrm{mg} / \mathrm{liter})$ as the TEB-S isolate $\left(\mathrm{EC}_{50}=0.45 \mathrm{mg} / \mathrm{liter}\right)$. In agreement with the statements by Liu et al. (27), this suggests, in the absence of cross-resistance, that alternation of active ingredients from the same chemical group (i.e., triazoles) may be an effective anti-resistance strategy for $F$. graminearum. Combining different triazole active ingredients in one commercial product may also delay selection for resistance to the individual compounds. Future research should assess the sensitivity of TEB-R isolates to prothioconazole, because the combination of tebuconazole with prothioconazole in Prosaro (Bayer CropScience LP) is now a widely used and efficacious product for suppression of FHB in North America (32).

In summary, our study demonstrates that most $F$. graminearum isolates from a representative sampling of the contemporary population infecting wheat spikes in New York are sensitive to the triazoles tested and documents the presence of an isolate that was significantly less sensitive to tebuconazole, highly aggressive, and toxigenic. Moreover, FHB control efficacy, in plants inoculated with the resistant isolate was strongly reduced using the commercial rate of tebuconazole under greenhouse conditions, where adequate fungicide coverage on wheat spikes is not the limitation that it can be in the field. Further studies on the epidemiology and monitoring of resistant isolates are crucial in order to better understand the risk that populations less sensitive to triazole fungicides pose to disease management and food security.

\section{Acknowledgments}

Laboratory, greenhouse, and field expenditures for this research were provided from Cornell University Hatch Project NYC153473. We thank the Programa de Pós-graduação em Fitotecnia (UFRGS) and CNPq-Conselho Nacional de desenvolvimento Científico e Tecnológico for providing a graduate scholarship and a sandwich fellowship to P. Spolti and the CNPq for a research fellowship for E. M. Del Ponte.

\section{Literature Cited}

1. Alexander, N. J., McCormick, S. P, Waalwijk, C. W, Lee, T. V. D., and Proctor, R. H. 2011. The genetic basis for 3-ADON and 15-ADON trichothecene chemotypes in Fusarium. Fungal Genet. Biol. 48:485-495.

2. Astolfi, P., Reynoso, M. M., Ramirez, M. L., Chulze, S. N., Alves, T. C. A., Tessmann, D. J., and Del Ponte, E. M. 2012. Genetic population structure and trichothecene genotypes of Fusarium graminearum isolated from wheat in southern Brazil. Plant Pathol. 61:289-295.

3. Becher, R., Hettwer, U., Karlovsky, P., Deising, H. B., and Wirsel, S. G. R. 2010. Adaptation of Fusarium graminearum to tebuconazole yielded descendants diverging for levels of fitness, fungicide resistance, virulence, and mycotoxin production. Phytopathology 100:444-453.

4. Blandino, M., Haidukowski, M., Pascale, M., Plizzari, L., Scudellari, D., and Reyneria, A. 2012. Integrated strategies for the control of Fusarium head blight and deoxynivalenol contamination in winter wheat. Field Crops Res. 133:139-149.

5. Buchenauer, H. 1987. Mechanism of action of triazol fungicides and related compounds. Pages 205-232 in: Modern Selective Fungicides. H. Lyr, ed. Gustav-Fischer-Verlag, Jena, Germany.

6. Burlakoti, R. R., Neate, S. M., Adhikari, T. B., Gyawali, S., Salas, B., Steffenson, B. J., and Schwarz, P. B. 2011. Trichothecene profiling and population genetic analysis of Gibberella zeae from barley in North Dakota and Minnesota. Phytopathology 101:687-695.

7. Chandler, E. A., Simpson, D. R., Thomsett, M. A., and Nicholson, P. 2003. Development of PCR assays to Tri7 and Tri13 trichothecene biosynthetic genes, and characterisation of chemotypes of Fusarium graminearum, Fusarium culmorum and Fusarium cerealis. Physiol. Mol. Plant Pathol. 62:355-367.

8. Cools, H. J., Mullins, J. G. L., Fraaije, B. A., Parker, J. E., Kelly, D. E., Lucas, J. A., and Kelly, S. L. 2011. Impact of recently emerged sterol $14 \alpha$-demethylase (CYP51) variants of Mycosphaerella graminicola on azole fungicide sensitivity. Appl. Environ. Microbiol. 77:3830-3837.

9. Cowen, L. E., Anderson, J. B., and Kohn, L. M. 2002. Evolution of drug resistance in Candida albicans. Annu. Rev. Microbiol. 56:139-165.

10. Cowger, C., and Arellano, C. 2013. Fusarium graminearum infection and deoxynivalenol concentrations during development of wheat spikes. Phytopathology 103:460-471.

11. Crane, J. M., Gibson, D. M., Vaughan, R. H., and Bergstrom, G. C. 2013. Iturin levels on wheat spikes linked to biological control of Fusarium head blight by Bacillus amyloliquefaciens. Phytopathology 103:146-155.

12. Cummings, J. A., Bergstrom, G. C., Richtmyer, R. J., III, and Hahn, R. R. 2013. Evaluation of foliar fungicides for control of Fusarium head blight and foliar diseases of winter wheat in New York, 2012. Plant Dis. Manage. Rep. 7:CF009.

13. Del Ponte, E. M., Fernandes, J. M. C., and Bergstrom, G. C. 2007. Influence of growth stage on Fusarium head blight and deoxynivalenol production in wheat. J. Phytopathol. 155:577-581.

14. Doukas, G. E., Markoglou, A. N., Vontas, J. G., and Ziogas, B. N. 2012. Effect of DMI-resistance mechanisms on cross-resistance patterns, fitness parameters and aflatoxin production in Aspergillus parasiticus Speare. Fungal Genet. Biol. 49:792-801.

15. Fuentes, R. G., Mickelson, H. R., Busch, R. H.., Dill-Macky, R., Evans, C. K., Thompson, W. G., Wiersma, J. V., Xie, W., Dong, Y., and Anderson, J. A. 2005. Resource allocation and cultivar stability in breeding for Fusarium head blight resistance in spring wheat. Crop Sci. 45:1965-1972.

16. Gale, L. R., Dill-Macky, R., Anderson, J. A., Smith, K. P., and Kistler, H. C. 2009. Aggressiveness and mycotoxin potential of U.S. Fusarium graminearum populations in fieldgrown wheat and barley. Page 173 in: Proc. 2009 Natl. Fusarium Head Blight Forum. S. Canty, A. Clark, J. Mundell, E. Walton, D. Ellis, and D. Van Sanford, eds. Orlando, FL.

17. Giavini, E., and Menegol, E. 2010. Are azole fungicides a teratogenic risk for human conceptus? Toxicol. Lett. 198:106-111.

18. Gilbert, J., and Haber, S. 2013. Overview of some recent research developments in Fusarium head blight of wheat. Can. J. Plant Pathol. 35:149-174.

19. Godet, F., and Limpert, E. 1998. Recent evolution of multiple resistance of Blumeria (Erysiphe) graminis f. sp. tritici to selected DMI and morpholine fungicides in France. Pestic. Sci. 54:244-252.

20. Hobbelen, P. H. F., Paveley, N. D., and van den Bosch, F. 2011. Delaying selection for fungicide insensitivity by mixing fungicides at a low and high risk of resistance development: A modeling analysis. Phytopathology 101:1224-1233.

21. Klix, M. B., Verreet, J.-A., and Beyer, M. 2007. Comparison of the declining triazole sensitivity of Gibberella zeae and increased sensitivity achieved by advances in triazole fungicide development. Crop Prot. 26:683-690.

22. Köller, W., Wilcox, W. F., Barnard, J., Jones, A. L., and Braun, P. G. 1997. Detection and quantification of resistance of Venturia inaequalis populations to sterol demethylation inhibitors. Phytopathology 87:184-190.

23. Kretschmer, M., Leroch, M., Mosbach, A., Walker, A.-S., Fillinger, S., Mernke, D., Schoonbeek, H.-J., Pradier, J.-M., Leroux, P., De Waard, M. A. and Hahn, M. 2009. Fungicide-driven evolution and molecular basis of multidrug resistance in field populations of the grey mould fungus Botrytis cinerea. PLoS Pathog. 5:e1000696. Online publication. doi:10.1371/ journal.ppat.1000696

24. Kuck, K. H., Scheinpflug, H., and Pontzen, R. 1995. DMI fungicides. Pages 205-258 in: Modern Selective Fungicides. H. Lyr, ed. Gustav-Fischer-Verlag, Jena, Germany.

25. Kulik, T., Łojko, M., Jestoi, M., and Perkowski, J. 2012. Sublethal concentrations of azoles induce tri transcript levels and trichothecene production in Fusarium graminearum. FEMS Microbiol. Lett. 335:58-67.

26. Leroux, P., Albertini, C., Gautier, A., Gredt, M., and Walker A.-S. 2007. Mutations in the CYP51 gene correlated with changes in sensitivity to sterol $14 \alpha$-demethylation inhibitors in field isolates of Mycosphaerella graminicola. Pest. Manage. Sci. 63:688-698.

27. Liu, X., Yu, F., Schnabel, G., Wua, J., Wang, Z., and Ma, Z. 2011. Paralogous cyp51 genes in Fusarium graminearum mediate differential sensitivity to sterol demethylation inhibitors. Fungal Genet. Biol. 48:113-123.

28. Ma, Z., and Michailides, T. J. 2005. Advances in understanding molecular mechanisms of fungicide resistance and molecular detection of resistant genotypes in phytopathogenic fungi. Crop Prot. 24:853-863.

29. Maldonado-Ramirez, S. L., Schmale, D. G., Shields, E. J., and Bergstrom, G. C. 2005. The relative abundance of viable spores of Gibberella zeae in the planetary boundary layer suggests the role of long-distance transport in regional epidemics of Fusarium head blight. Agric. For. Meterol. 132:20-27.

30. Mavroeidi, V. I., and Shaw, M. W. 2005. Sensitivity distributions and crossresistance patterns of Mycosphaerella graminicola to fluquinconazole, prochloraz and azoxystrobin over a period of 9 years. Crop Prot. 24:259-266.

31. McCallum, B. D., Tekauz, A., and Gilbert, J. 2004. Barrage zone formation between vegetatively incompatible Fusarium graminearum (Gibberella zeae) isolates. Phytopathology 94:432-437.

32. McMullen, M., Bergstrom, G., De Wolf, E., Dill-Macky, R., Hershman, D., Shaner, G., and Van Sanford, D. V. 2012. A unified effort to fight an enemy of wheat and barley: Fusarium head blight. Plant Dis. 96:1712-1728.

33. Mugrabi de Kuppler, A. L., Steiner, U., Sulyok, M., Krska, R., and Oerke, E. C. 2011. Genotyping and phenotyping of Fusarium graminearum isolates from Germany related to their mycotoxin biosynthesis. Int. J. Food Microbiol. 151:78-86.

34. Nakajima, T. 2010. Fungicides application against Fusarium head blight in wheat and barley for ensuring food safety. Pages 139-156 in: Fungicides. O. Carisse, ed. InTech, Rijeka, Croatia.

35. Pan, D., Calero, N., Mionetto, A., and Bettucci, L. 2013. Trichothecene genotypes of Fusarium graminearum from wheat in Uruguay. Int. J. Food Microbiol. 162:120-123.

36. Paul, P. A., Lipps, P. E., Hershman, D. E., McMullen, M. P., Draper, M. A., and Madden, L. V. 2008. Efficacy of triazole-based fungicides for Fusarium head blight and deoxynivalenol control in wheat: a multivariate meta-analy- 
sis. Phytopathology 98:999-1011.

37. Paul, P. A., McMullen, M. P., Hershman, D. E., and Madden, L. V. 2010. Meta-analysis of the effects of triazole-based fungicides on wheat yield and test weight as influenced by Fusarium head blight intensity. Phytopathology 100:160-171.

38. Pirgozliev, S. R., Edwards, S. J., Hare, M. C., and Jenkinson, P. 2002. Effect of dose rate of azoxystrobin and metconazole on the development of Fusarium head blight and the accumulation of deoxynivalenol (DON) in wheat grain. Eur. J. Plant Pathol. 108:469-478.

39. Puri, K. D., and Zhong, S. 2010. The 3ADON population of Fusarium graminearum found in North Dakota is more aggressive and produces a higher level of DON than the prevalent 15ADON population in spring wheat. Phytopathology 100:1007-1014

40. Schmale, D. G., III, Arntsen, Q. A., and Bergstrom, G. C. 2005. The forcible discharge distance of ascospores of Gibberella zeae. Can. J. Plant Pathol. 27:376-382.

41. Schmale, D. G., III, Leslie, J. F., Saleh, A. A., Shields, E. J., and Bergstrom, G. C. 2006. Genetic structure of atmospheric populations of Gibberella zeae. Phytopathology 96:1021-1026.

42. Schmale, D. G., III, Tallapragada, P., Dingus, B., Ross, S. D., Fetters, T. L., Wood-Jones, A. K. 2011. Isolates of Fusarium graminearum collected 40320 meters above ground level cause Fusarium head blight in wheat and produce trichothecene mycotoxins. Aerobiologia 28:1-11.

43. Schmale, D. G., III, Wood-Jones, A. K., Cowger, C., Bergstrom, G. C., and Arellano, C. 2011. Trichothecene genotypes of Gibberella zeae from winter wheat fields in the eastern USA. Plant Pathol. 60:909-917.

44. Spolti, P., Del Ponte, E. M., Cummings, J. A., Dong, Y., and Bergstrom, G. C. 2014. Fitness attributes of Fusarium graminearum isolates from wheat in New York possessing a 3-ADON or 15-ADON trichothecene genotype. Phytopathology 104:513-519.

45. Spolti, P., de Jorge, B. C., and Del Ponte E. M. 2012. Sensitivity of Fusarium graminearum causing head blight of wheat in Brazil to tebuconazole and metconazole fungicides. Trop. Plant Pathol. 37:419-423.

46. Stehmann, C., and De Waard, M. A. 1996. Sensitivity of populations of Botrytis cinerea to triazoles, benomyl and vinclozolin. Eur. J. Plant Pathol. 102:171-180.

47. Suzuki, F., Yamaguchi, J., Koba, A., Nakajima, T., and Arai, M. 2007. Changes in fungicide resistance frequency and population structure of Pyricularia oryzae after discontinuance of MBI-D fungicides. Plant Dis. 94:329-334.

48. Tateishi, T., Miyake, T., Mori, M., Kimura, R., Sakuma, Y., and Saishoji, T. 2010. Sensitivity of Japanese Fusarium graminearum species complex isolates to metconazole. J. Pestic. Sci. 35:419-430.

49. Von der Ohe, C., Gauthier, V., Tamburic-Ilincic, L., Brule-Babel, A., Fernando, W. G. D., Clear, R., Ward, T. J., and Miedaner, T. 2010. A comparison of aggressiveness and deoxynivalenol production between Canadian Fusarium graminearum isolates with 3 -acetyl and 15-acetyldeoxynivalenol chemotypes in field-grown spring wheat. Eur. J. Plant Pathol. 127:407-417.

50. Von der Ohe, C., and Miedaner, T. 2011. Competitive aggressiveness in binary mixtures of Fusarium graminearum and F. culmorum isolates inoculated on spring wheat with highly effective resistance QTL. J. Phytopathol. 159:401-410.

51. Walker, S. L., Leath, S., Hagler, W. M., Jr., and Murphy, J. P. 2001. Variation among isolates of Fusarium graminearum associated with Fusarium head blight in North Carolina. Plant Dis. 85:404-410.

52. Wallhead, M., Madden, L., and Paul, P. 2007. Differential sensitivity to triazole-based fungicides among isolates of Fusarium graminearum. Page 141 in: Proc. 2007 Natl. Fusarium Head Blight Forum. Michigan State University, East Lansing.

53. Ward, T. J., Bielawski, J. P., Kistler, H. C., Sullivan, E., and O'Donnell, K. 2002. Ancestral polymorphisms and adaptive evolution in the tricothecene mycotoxin gene cluster of phytopathogenic Fusarium. Proc. Natl. Acad. Sci. USA 99:9278-9283.

54. Ward, T. J., Clear, R. M., Rooney, A. P., O’Donnell, K., Gaba, D., Patrick, S., Starkey, D. E., Gilbert, J., Geiser, D. M., and Nowicki, T. W. 2008. An adaptive evolutionary shift in Fusarium head blight pathogen populations is driving the rapid spread of more toxigenic Fusarium graminearum in North America. Fungal Genet. Biol. 45:473-484.

55. Waxman, K. D., Bergstrom, G. C., Richtmyer, R. J., III, and Hahn, R. R. 2012. Evaluation of foliar fungicides for control of Fusarium head blight of winter wheat in New York, 2011. Plant Dis. Manage. Rep. 6:CF009.

56. Wegulo, S. N., Zwingman, M. V., Breathnach, J. A., and Baenziger, P. S. 2011. Economic returns from fungicide application to control foliar fungal diseases in winter wheat. Crop Prot. 30:685-692.

57. Willyerd, K. T., Li, C., Madden, L. V., Bradley, C. A., Bergstrom, G. C., Sweets, L. E., McMullen, M., Ransom, J. K., Grybauskas, A., Osborne, L., Wegulo, S. N., Hershman, D. E., Wise, K., Bockus, W. W., Groth, D., DillMacky, R., Milus, E., Esker, P. D., Waxman, K. D., Adee, E. A., Ebelhar, S. E., Young, B. G., and Paul, P. A. 2012. Efficacy and stability of integrating fungicide and cultivar resistance to manage Fusarium head blight and deoxynivalenol in wheat. Plant Dis. 96:957-967.

58. Wong, F. P., and Midland, S. L. 2007. Sensitivity distributions of California populations of Colletotrichum cereale to the DMI fungicides propiconazole, myclobutanil, tebuconazole, and triadimefon. Plant Dis. 91:1547-1555.

59. Yin, Y., Liu, X., Li, B., and Ma, Z. 2009. Characterization of sterol demethylation inhibitor-resistant isolates of Fusarium asiaticum and F. graminearum collected from wheat in China. Phytopathology 99:487-497.

60. Zeller, K. A., Bowden, R. L., and Leslie, J. F. 2003. Diversity of epidemic populations of Gibberella zeae from small quadrats in Kansas and North Dakota. Phytopathology 93:874-880.

61. Zhang, Y. J., Yu, J. J., Zhang, Y. N., Zhang, X., Cheng, C. J., Wang, J. X., Hollomon, D. W., Fan, P. S., and Zhou, M. G. 2010. Effect of carbendazim resistance on trichothecene production and aggressiveness of Fusarium graminearum. Mol. Plant-Microbe Interact. 22:1143-1150. 